\title{
International Comparative Study on Computational Thinking Education in K-12
}

\author{
Yang Xing ${ }^{1, *}$, Yan Zhang ${ }^{2}$ \\ ${ }^{1}$ Department of Education, Beijing Normal University, Beijing, China. \\ ${ }^{2}$ Department of Education, Hebei University, Baoding, China.
}

\begin{abstract}
How to cite this paper: Yang Xing, Yan Zhang. (2020). International Comparative Study on Computational Thinking Education in K-12. The Educational Review, USA, 4(8), 166-175.

DOI: $10.26855 /$ er.2020.08.002
\end{abstract}

Received: July 30, 2020

Accepted: August 21, 2020

Published: August 26, 2020

Corresponding author: Yang Xing, Department of Education, Beijing Normal University, Beijing, China.

Email: xywzy468129@163.com

\begin{abstract}
As a new product of the computing age, computational thinking is considered to be a thinking method and strategy by using computational tools and methods to solve problems. It has the potential to play a vital role in the overall and lifelong development of everyone. In recent years, computational thinking education has gradually approached the horizons of educational researchers. However, the development of research and practice are still in the early stage. The questions such as unclear research objectives, not extensive research levels and not deep research issues are gradually revealed. What and how to teach become a huge problem for frontline teachers. In order to find out strategic measures to solve practical problems, we selected USA, England, Lithuania, France and China as the research object. Each country has its own plan to develop CT at the K-12 stage. With the focus on CT education, the purpose of this paper is to compare and discuss the representative development path through the lens of international perspectives and cultural contexts to provide a general framework of CT education across the globe. We divide the whole framework into three parts: production, learning, and research. And we describe the framework as a tree, and the branches represent the dimensions, consisting of five parts: policy-making, non-profit organization, industry promotion, teacher training, course implementation. Each dimension is related to each other and echoes each other to form a large whole system. The root of the tree represents the needs of students, indicates that all the dimensions are to serve for students. The aim is to develop computational thinking, logical thinking, digital competences of the students who need to prepare for the digital world.
\end{abstract}

\section{Keywords}

Computational Thinking, Computational Thinking Education, Computer Science, Digital Economy, General Framework

\section{Introduction}

Nowadays, the word of "intelligence" has become a part of our life. The wonderful relationship between "artificial intelligence" and "humanity" has always been a hot topic of discussion, and there exist "replacement theory" and "control theory". In order not to be eliminated by the intelligent society, ideas and methods will become the basic survival skills residents of the intelligent era need. In recent years, we have witnessed an active discussion surrounding the important role of computational thinking (CT). Therefore, the owner of computational thinking should be the general public, and computational thinking education should be given high priority. 
The main goal of CT education is to prepare the younger generations for the opportunities and challenges of the future economy where computing permeates virtually every aspect of society, regardless of their ultimate field of study or occupation (Computing in the core, 2019). For example, in the process of learning computer science, students need to do more than just the application of new technologies, but complete the process of de-construction and reconstruction based on understanding. The development of the future society also calls for the talent who owns new ability such as creativity, curiosity and critical thinking.

As a result, many countries favor the development of CT education: the three pillars of politics, economy and education support each other. Not only does it own national policy support, the promotion of the economic industry, but also it has theoretical and practical explorations in education. The way in which CT education is promoted varies. Some national education departments issue relevant policies, carry out curriculum reforms or integrate CT as an independent discipline in the K-12 stage. Besides, strong economic industries such as Google, Microsoft have also joined the wave of promotion, using their own advantages to create a platform. For example, Google has a dedicated website for CT education (www.google.com/edu/computationalthinking) which publishes videos related to CT, providing teachers with different teaching methods and relevant resources for educators and managers.

\section{Understanding Computational Thinking}

\subsection{Definition of CT}

Computational thinking, a term mentioned by Papert in 1980 (Papert, 1980), generate attraction from researchers, practitioners and policy makers in the education field since 2006, through a seminal article by Wing (2016), defined as a series of thinking activities that cover the breadth of computer science, such as problem solving, system design, and human behavior understanding, using the basic concepts of computer science. At the same time, other scholars also have their own interpretation of CT. The Computer Science Teachers Association and the International Society for Technology in Education (CSTA \& ISTE, 2009) have developed an operational definition that provides a framework and vocabulary for computational thinking:

Computational Thinking (CT) is a problem-solving process that includes (but is not limited to) the following characteristics:

- Formulating problems in a way that enables us to use a computer and other tools to help solve them;

- Logically organizing and analyzing data;

- Representing data through abstractions such as models and simulations;

- Automating solutions through algorithmic thinking (a series of ordered steps);

- Identifying, analyzing, and implementing possible solutions with the goal of achieving the most efficient and effective combination of steps and resources;

- Generalizing and transferring this problem-solving process to a wide variety of problems.

In August 2016, the CSTA released the K-12 Computer Science Standards. This stresses the problem-solving aspects, as well as abstraction, automation, and analysis as distinctive elements of CT: "We believe that computational thinking is a problem-solving methodology that expands the realm of computer science into all disciplines, providing a distinct means of analyzing and developing solutions to problems that can be solved computationally. With its focus on abstraction, automation, and analysis, CT is a core element of the broader discipline of computer science” (CSTA, 2017).

\subsection{CT's relationship with programming}

Computer Science is considered as the established academic term for the scientific discipline underlying the current digitalization and information technology (Heintz, Mannila, \& Färnqvist, 2016). And programming learning is the focus of computer science teaching. There are examples of countries around the world where programming or CS has been or will be introduced into early childhood education. For example, the European School net (October 2015) published a report surveying the current initiatives and plans in 20 European countries:16 countries integrate coding in the curriculum at national, regional or local level: Austria, Bulgaria, the Czech Republic, Denmark, Estonia, France, Hungary, Ireland, Israel, Lithuania, Malta, Spain, Poland, Portugal, Slovakia and the UK (European Schoolnet,2015). The analysis of many sources reveals that a variety of terms concerning CT are used including coding, programming, informatics, algorithmic thinking and so on. It can be seen that computational thinking and programming are closely related. But does programming education equal to CT education? What's the deep relationship between programming and CT?

Based on the understanding of the running process of computer programs, programming is the method to achieve the control of the computer. It belongs to the tool level. However, CT covers not only the technical layer, but also the 
thinking of using tools and methods to solve problems. In general, it is agreed that CT and programming are not overlapping sets: "thinking as a computer scientist means more than being able to program a computer" (CSTA \& ISTE, 2009). Although programming plays an important role in the development of CT, it's only part of it. In addition, CT includes other core ideas such as problem decomposition and abstraction, which are more based on the reality of life. The ultimate goal of CT education is to solve real problems. It is difficult to achieve this high requirement only through programming skills training.

Despite these distinctions, programming can make CT concepts more concrete and become a tool for learning. During the process of learning, the art of programming changes the children perspectives from application users to application creators so that they can express themselves freely. Last but not least, it also provides an opportunity to incorporate CT into other subjects, which is helpful to develop digital literacy and information literacy from an interdisciplinary perspective.

\section{Objectives and Related Work}

Scoping reviews of the CT education around the world and the country report have been conducted in the past but they only focus on the single aspect such as the policy, assessment, teacher development or the experience of teaching. However, these factors are not combined to form a large framework system. Among them, the European SchoolNet report description is more comprehensive, involving CT definition, integration with curriculum, programming skills assessment, teacher training and many other aspects (European Schoolnet, 2015). As for the area of practice, Fredrik et al. reviewed how ten different countries have approached introducing computing into their K-12 education. The most common model was to make it compulsory in primary school and elective in secondary school (Heintz, Mannila, \& Färnqvist, 2016). Shuchi et al. summarized pertinent research on CT in K-12 involving the environment, tools and assessment (Grover \& Pea, 2013). Furthermore, in order to help teachers involve in teacher education and decision makers understand how and when CT can be included in their local institutions, Linda et al. discussed the current state of CT in K-9 education in multiple countries in Europe as well as the United States (Mannila, Amber., \& Dagiene et al, 2014). And Nicol R. interviewed five educational technology leaders with CS expertise from California, Florida, New Jersey, Missouri, and Maryland to collect the state's support for CS program teachers (Howard, 2018). As for policy, Yu-Chang et al. analyzed Reports, white papers, and policy documents across the global, summarizing four development trends: collaboration and partnerships across sectors and national boundaries, rationales taking a broad perspective and referring to common themes, a redefinition of digital competence, and an emphasis on broadening access and interest (Hsu, Irie, \& Ching, 2019). Stefania et al. discussed the most significant CT developments for compulsory education in Europe and provided a comprehensive synthesis of evidence, including implications for policy and practice (Engelhardt, 2016).

The International Computational Thinking Bebras Challenge is dedicated to developing the thinking skills of 3-18 years old, founded in Lithuania in 2004. It has been held for sixteen years. Analyzing data of 2018 Challenge (Figure 1), we found that the number of the French participants is the most, equaling to dozens of times of other countries. And the USA, England, China also encourage students to participate in the challenge. In order to explore the idea of curriculum reform such as "British computing course”, “American computer science for all campaign”, we selected USA, England, Australia, Lithuania, France and China as the research object. Our goal is to contribute to the discussion around early education by: 1) exploring the status of CT in K-12 education from different countries; 2) exploring why the studied countries develop the CT perfectly; 3) constructing the general development framework for CT education; 4) preparing ideas and guidelines for collaboration and partnerships to introduce and enhance CT in the global education

\section{Status of CT in Education}

Despite this widespread interest, successful CT integration in K-12 education still faces unresolved issues. It has presented some challenges for educators, as computing has traditionally been primarily a university level discipline, there are no widely accepted general standards for what computing at K-12 level entails (Heintz, Mannila, \& Färnqvist, 2016). Through the analysis of domestic research literature, it is found that CT education research is still in its infancy. $80 \%$ of the research involves CS courses in higher education, and K-12 researches focus on the information technology curriculum, lacking interdisciplinary integration education. After interviewing with primary and secondary school teachers in Beijing, China, it is found that most of the teachers don't have a background in CS and they are not familiar with the basic concepts of CS. The frontline teachers are very appreciative of the importance of developing students' CT in the basic education stage, but there isn't a clear curriculum system. It is difficult to combine CT with the courses currently taught. What and how to teach becomes the biggest problem facing teachers. Not to mention the assessment. 


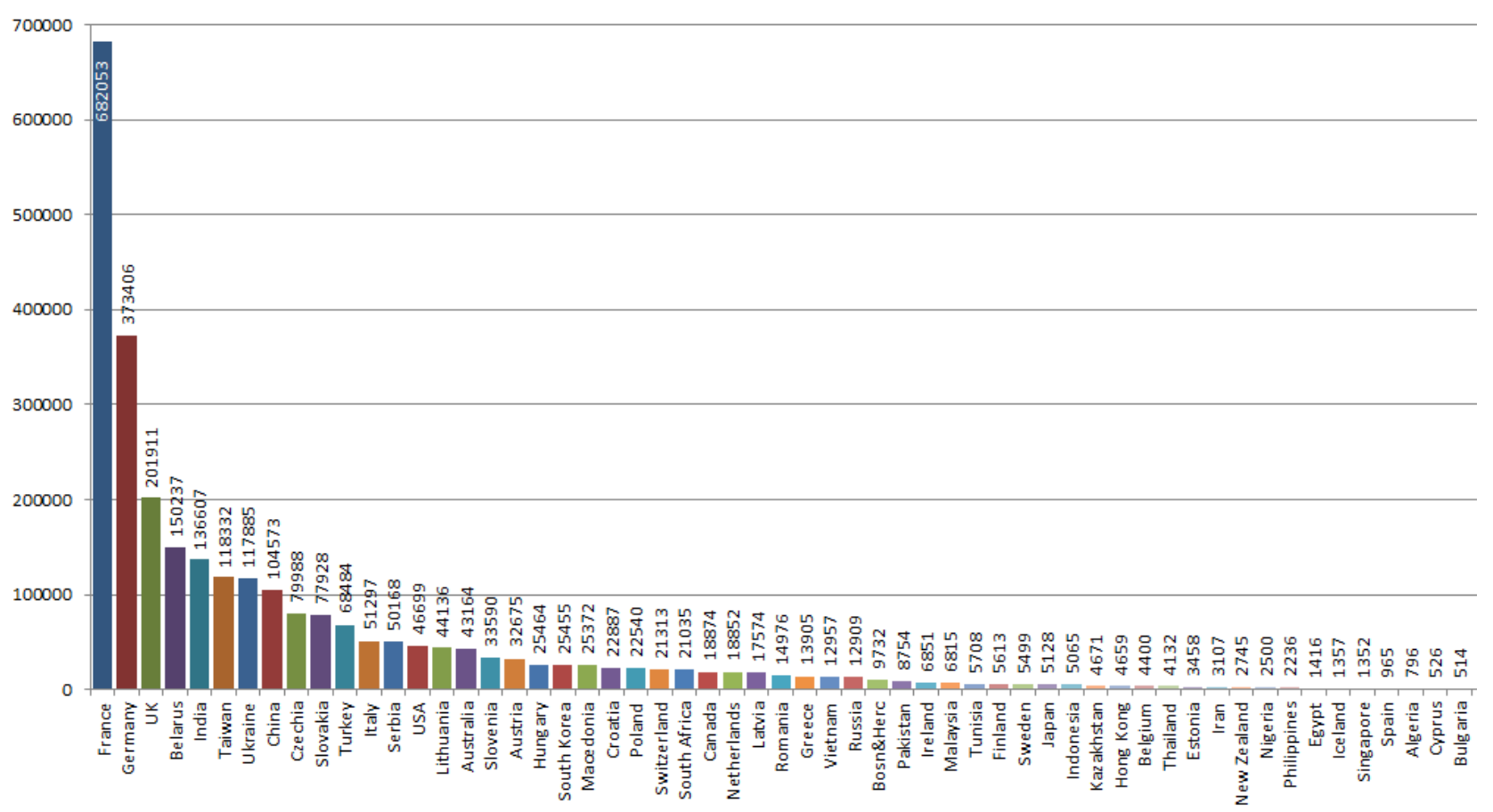

Figure 1. The statistics of the participants in Bebras Challenge 2018 from countries.

Based on the domestic CT education issues, this study summarizes the development experiences of other countries (USA, England, Lithuania, France) and explores the possibility of mutual learning, cooperation and interaction between countries to promote common development. To study ways and models for how CS or CT can be introduced, we select the following criteria to focus on:

- Policy-making;

- Role in primary and secondary level curriculum (compulsory/elective/other);

- Integrated or a subject of its own;

- Computingtools and assessment;

- Teacher training (in-service and pre-service);

- Organizational support;

- Economic industry promotion;

\section{Country reports}

\subsection{USA}

In USA, the control of education primarily depends on the state and local government, which represents that the status of CS may vary significantly across the states. But there is a national program named "computer science for all" in 2016, initiated by President Obama's bold new initiative to empower a generation of American students with the computer science skills they need to thrive in a digital economy(White House, 2016). During the process, every state promotes CS education in the K-12 stage actively. In order to keep high quality, they provide the teachers with training for their own CT skills. Moreover, businesses and philanthropies like Apple, Facebook, Microsoft and Code.org have also played a major role in building a movement to expand CS nationally. For example, Microsoft announces its campaign to have all states adopt "Make CS Count" policies and invest in CS education as a complement to existing \$75 million initiative.

There is also a great effort the main organizations including ACM, CSTA, Code.org, CIC, and NMSI make to develop a Framework for K-12 Computer Science Education (https://k12cs.org/). The framework consists of five percepts and seven practices. States, districts, and organizations can use the framework to inform the development of standards and curriculum, build capacity for teaching computer science and implement computer science pathways. It concentrates on the following issues: What should be taught and what the children can do after graduation? How to carry out 
CS education in early childhood? How to plan a course to ensure the effective connection of compulsory and secondary education? How to assess the development of CT?

However, there are few places in the USA where CS is required for students. At best, high school students have the option of taking electives in technology or, in some places, taking the Advanced Placement Computer Science course which is currently a Java programming class. The CS AP course allows students to take a standardized test, which if they pass, provides them with college credit (Mannila, Amber. \& Dagiene et al., 2014). This new focus on computational thinking has been further supported by an educational programming renaissance that has brought about the development of new computer science teaching tools (for example Alice, AgentSheet, Blockly, Kodu and Scratch).

Teachers in the US are required to receive their primary teacher certification in some discipline other than computer science and then meet additional requirements to receive a supplemental computer science endorsement (GalEzer \& Chris, 2014). The gap between the availability of teacher certifications or endorsements and the requirement to teach CS subjects is of great concern. Luckily, the generous funding from the National Science Foundation, from industry leaders such as Google and Oracle, and from CSTA makes Efforts to develop teacher training programs (GalEzer \& Chris, 2014).

\subsection{England}

With the changes in the digital age, the "tools" curriculum information communication technology that cultivates students' software application capabilities has been questioned by British academics and industry. In October 2012, to ensure Britain competes and thrives in the global race, the government sets out plans to boost the teaching of computer science, supported by industry experts such as Microsoft, Facebook, BT and IBM (Britain education, 2019). In January 2013, because of the importance of computer science for both education and the economy, the government announced that it was included in the EBacc exam (Department for Education, UK, 2019). In February 2013, the Ministry of Education announced that the new curriculum, computing, was officially implemented, replacing the original ICT curriculum and taking computational thinking as the core goal of the course (Computing at School, 2019). Therefore, the UK chose to set up an independent curriculum to develop student computing thinking, rather than using programming as an intermediary for development.

The content of the Computing course mainly involves three aspects: computer science, information technology and digital literacy. The course objectives are divided into four phases, covering both primary and secondary education. The main aims are to ensure that all students (Department for Education, 2013):

- can understand and apply the fundamental principles and concepts of computer science, including abstraction, logic, algorithms and data representation;

- can analyze problems in computational terms, and have repeated the practical experience of writing computer programs to solve such problems;

- can evaluate and apply information technology, including new or unfamiliar technologies, analytically to solve problems responsible, competent, confident and creative users of information and communication technology.

To ensure every child in every school has the right to world-class computing education, a community called CAS (Computing at school) established, supported financially by BCS, Microsoft, Google, Ensoft and the UK Committee of Heads and Professors of Computer Science. Unlike an organizer, CAS is more like a public platform where teachers and experts can share their understanding of computing courses, interact what difficulties they encounter during student performance, improve the structure of the curriculum, and improve the quality of teaching. At the same time, CAS provides instructional programs and instructional syllabus for each stage, from the most basic teaching essential resources to the high-level activity curriculum pro-grams, including Barefoot Computing and Quick Start Computing and Teach Primary Computing for primary educators.

The teachers who are currently employed in a school and delivering computing lessons can take part in the teacher training of CAS. And the participants who satisfy the required credit can get a certification of BCS to recognize their computing knowledge and ability. In addition, CAS executes a project which trials some new initiatives aimed at improving girls' participation in computing.

\subsection{Lithuania}

In Lithuania, CS is referred to as informatics. The first few after-school classes in programming were established in several Lithuanian secondary schools in 1970-1975. There also appeared the first ideas to establish a school to teach secondary school students programming (Dagiene, 2006). So teaching informatics started in the early 1980s with programming. As a part of the Education Reform in 1997, the informatics core curriculum went through a major revision 
and it was expanded from teaching two years to four years (in total 136 hours) with more focus on application and the processing of information (Dagiene \& Stupuriene, 2016). After the new reform of secondary schools in 2005, the subject "informatics" is rename "Information Technology". And the main attention of schools was paid to satisfy students' need and foster computer literacy.

Methodology on teaching CS at secondary school level was strong and well de-signed by Lithuanian's researchers. The IT subject is taught by IT teachers who have various types of training. Some of them have a CS or mathematics degree combined with education, while others are teachers of other subjects with little training in IT. The students of grades 5-10 are required to take part in the course 1 hour per week. IT includes five knowledge areas: information; digital technologies; algorithms and programming; virtual communication; security, ethics and legal principles. At the upper secondary level (grade 11-12), IT is an elective subject offered in basic and advanced modes. The advanced course includes electronic publishing, database de-sign and management, and programming (Dagiene \&Stupuriene, 2016).

Apart from the course, there are also exams and contests concerning informatics. The curriculum of Informatics exam closely corresponds to the content of the programming module. Three main fields are emphasized: algorithms, data types and structures, and constructs of a programming language (Benaya, Zur., Dagiene, \& Stupuriene, 2017). To introduce CS concepts, some interesting tasks related to real life with the knowledge of CS are set up for different age students. The international challenge on Informatics and Computational Thinking Bebras focuses on concepts-based tasks. All students in secondary education under the age of 20 are invited to compete in Lithuanian Olympiads in Informatics. These tasks can include a wide range of concepts within CS including algorithms and programs, both sequential and concurrent; data structures like heaps, stacks and queues; modelling of states, control flow and data flow; human-computer interaction; etc.

\subsection{France}

The history of informatics education in France has some similarities with other European countries. In the 1980s, informatics was referred as a new elective course in senior high schools (Mannila, Amber. \& Dagiene et al., 2014). But there exists statement that the goal of the course was not to teach programming languages, but to promote the algorithmic way of thinking as being useful for all other subjects (Baron, 1989). Since then, there has been a constant debate about whether it should be a separate discipline or an aid to other disciplines.

Many years later, some scholars realized the importance of computer science to the future development of students, the Ministry of Education is also gradually concerned. As for elementary school, the curriculum covering programming, unplugged activities et al. is established by groups of experts-the Superior Curricula Council, ap-pointed by the MoE. During the process, the teacher may advisory the researcher for specific points, usually more technical or unclear content (Vanea \& Laure, 2016). As for secondary school, in 2012, algorithmic was introduced in mathematics curricula at grade 11 and an elective Computer Science course (called ISN) has been introduced at grade 12. The ISN course adopted project-based learning and teaching methods and it was structured into four themes: information comprehension, algorithmic, languages and programming, computer architecture. Students' learning in ISN must be assessed during an oral presentation of the outcomes of one of the projects they worked for during the year. In September 2015, the Superior Curricula Council proposed new curricula for kindergarten, elementary and middle school (Conseil, 2015).

The educators for ISN could be teachers from scientific subject matter (mathematics, physics and chemistry) and technological subject matters (applied and industrial sciences). All teachers were motivated and had inclinations towards digital literacy, but none had previous knowledge of programming. So most ES teachers are trained mainly by Superior Schools of Teaching and Education-SSTE (Ecoles sup'erieures du professor at et de l'education) which deliver them a master (Benaya, Zur., Dagiene, \& Stupuriene, 2017). Beside this, begun in France in 2016, Class' Code is a consortium of universities, companies and the government, offering educators who work with children ages 8-14 free online CT courses and resources as well as face-to-face meetings with facilitators throughout France (Hsu, Irie, \& Ching, 2019).

\subsection{China}

In China, computer science is usually offered at a university, and it's called information technology in primary and secondary school. However, it is not an assessment subject for important exams (such as college entrance examinations). In the context of exam-oriented education, CS and computing education has long been decontextualized and considered irrelevant by many students. However, since 2007, China has progressively transformed and restructured computing education through CSO (College Computers course) reform by integrating CT into the curriculum. The CS0 reform took four different approaches/contexts/content areas, including "CS0 course for the deaf”, a MOOC on C Programming, a MOOC on College Computers and a CS0 course designed for health majors (Pan, Rich, \& Hodges, 2017). 
As computational Thinking and related concepts (e.g. coding, programming, algorithmic thinking) have received increasing attention in the educational field, introducing them into compulsory K-12 classes becomes necessary. Although Chinese CT education started late, it has also been moving forward. In 2017, the Ministry of Education issued the "Standards for Information Technology Courses in Ordinary High Schools" in which CT was regarded as one of the core literacy of information technology disciplines. The original information literacy goal was further developed into digital literacy, creative ability, and computational thinking. The course is set to compulsory, elective, and optional compulsory subjects, including artificial intelligence, 3D design, open source hardware, database, information system and other subjects (Ministry of Education of the People’s Republic of China, 2018). Moreover, the new college entrance examination reform program piloted in Zhejiang Province includes the information technology course in the seven-choice three subjects. It is the first time that information technology is recognized as the assessment subject in the key examinations (Ministry of Education of the People's Republic of China, 2019). The emergence of computational thinking has injected new vitality into the information technology curriculum.

In the practice of CT training, in addition to a small number of unplugged computer science gamification activities, programming is widely recognized as an effective way Graphical programming tools Scratch and App Inventor become the first choice.

\section{Summary and Conclusions}

Different countries have different institutional settings according to their own development, but education is global and extensive, regardless of country. To adapt to the future economic development, the education departments of various countries pay more attention to the thinking training of students in K-12. The visible hand of "policy" and the invisible hand of "industry" form a huge educational circle to promote the development of CT education jointly. With the focus on CT education, we select USA, England, Lithuania, France and China as the research object. Each country has its own plan to develop CT in K-12:

Table 1. Table type styles (Table caption is indispensable)

\begin{tabular}{|c|c|c|c|c|c|}
\hline Country & USA & England & Lithuania & France & China \\
\hline Subject & $\begin{array}{l}\text { Computer Science } \\
\text { (own subject ) }\end{array}$ & $\begin{array}{l}\text { Computing } \\
\text { (own subject) }\end{array}$ & $\begin{array}{l}\text { Information tech- } \\
\text { nology } \\
\text { (own subject) }\end{array}$ & $\begin{array}{l}\text { Computer Science } \\
\text { course(own subject), } \\
\text { Mathematics } \\
\text { (integrated) }\end{array}$ & $\begin{array}{c}\text { Information tech- } \\
\text { nology } \\
\text { (own subject) }\end{array}$ \\
\hline $\begin{array}{l}\text { Prima- } \\
\text { ry/secondary }\end{array}$ & $\begin{array}{l}\text { compulsory/ } \\
\text { compulsory }\end{array}$ & Compulsory & $\begin{array}{l}\text { compulsory/ } \\
\text { elective }\end{array}$ & elective & $\begin{array}{l}\text { compulsory/ } \\
\text { compulsory } \\
\text { elective }\end{array}$ \\
\hline Focus & $\begin{array}{l}\text { computational } \\
\text { thinking, } \\
\text { critical thinking }\end{array}$ & $\begin{array}{l}\text { computational } \\
\text { thinking, } \\
\text { computer science }\end{array}$ & $\begin{array}{l}\text { computational } \\
\text { thinking, } \\
\text { CS knowledge }\end{array}$ & $\begin{array}{l}\text { information compre- } \\
\text { hension, algorithmic, } \\
\text { computer architecture }\end{array}$ & $\begin{array}{l}\text { programming } \\
\text { knowledge, } \\
\text { digital literacy }\end{array}$ \\
\hline Tools & $\begin{array}{l}\text { programming lan- } \\
\text { guage, graphical } \\
\text { programming }\end{array}$ & $\begin{array}{l}\text { Programing lan- } \\
\text { guage, graphical- } \\
\text { programming }\end{array}$ & $\begin{array}{l}\text { Programminglan- } \\
\text { guage }\end{array}$ & $\begin{array}{c}\text { programming } \\
\text { unplugged activities }\end{array}$ & $\begin{array}{l}\text { Programming } \\
\text { graphical pro- } \\
\text { gramming }\end{array}$ \\
\hline $\begin{array}{c}\text { Assess- } \\
\text { ment/exam }\end{array}$ & standardized test & EBacc exam & exams and contests & national exam & $\begin{array}{l}\text { exams and } \\
\text { contests }\end{array}$ \\
\hline $\begin{array}{l}\text { organiza- } \\
\text { tional sup- } \\
\text { port }\end{array}$ & $\begin{array}{c}\text { Apple, Micr } \\
\text { osoft, Facebook, } \\
\text { code.org, ACM, } \\
\text { CSTA, CIC, NMSI }\end{array}$ & $\begin{array}{c}\text { Microsoft, } \\
\text { Google, IntelFace- } \\
\text { book, } \\
\text { BT, IBM, BCS, } \\
\text { CAS }\end{array}$ & / & $\begin{array}{l}\text { SSTE, SCC, } \\
\text { Clss'Code }\end{array}$ & $\mathrm{CCF}$ \\
\hline $\begin{array}{l}\text { Characteris- } \\
\text { tic }\end{array}$ & $\begin{array}{l}\text { k-12 framework, } \\
\text { five percepts, } \\
\text { seven practices }\end{array}$ & $\begin{array}{l}\text { CAS: a public plat- } \\
\text { form }\end{array}$ & Bebras Challenge & $\begin{array}{l}\text { Coteaching between } \\
\text { teachers and re- } \\
\text { searchers }\end{array}$ & l \\
\hline
\end{tabular}

As shown above, we can conclude that economic industry and non-profit organizations play an important role in the process of curriculum reform in some countries (the USA, England). On the one hand, non-profit organizations call 
together experts, researchers and teachers who are committed to the development of CS. On the other hand, financial support of the industry funds for the teacher training, curriculum development and other aspects of the project. In addition, the UK focuses on establishing an open communication platform, listening to the voices of each participant and solving problems together. There're also countries with institutional support, as well as France, but the most impressive point is the joint teaching of educators and researchers. It shows that the close integration of educational theory and practice, which can be known as a model of education. Lithuania, the founding member of the Bebras Challenge, is very different and has always attracted students' interest in CS with the Bebras Challenge and the Informatics Olympics.

\section{Suggestion and Future Prospects}

However, CT is referred to as a way of thinking. Its most evident characteristic is abstraction. So we think it is not appropriate to say "cultivation" but to say "development". The purpose of this paper is to compare and discuss the representative development path through the lens of international perspectives and cultural contexts to provide a general framework of CT education across the globe.

After summarizing, we divide the whole framework into three parts: production, learning, and research. And we describe the framework as a tree, the branches represent the frame dimensions, consisting of five parts: policy making, non-profit organization, industry promotion, teacher training, course implementation. Each dimension is related to each other and echoes each other to form a large whole. The root of the tree represents the needs of students, indicates that all the dimensions are to serve for students. The aim is to develop computational thinking, logical thinking, digital competences of the students who need to prepare for the digital world. The Ministry of Education usually releases guidance document which the schools and organizations must follow. The document usually brings together a variety of stakeholders, including students, parents, teachers, administrators, universities, industry leaders, nonprofits and government agencies. It also charges for the certificate qualification of the teachers and the requirement teachers should satisfy. The most important part is course implementation in that students can exercise their thinking and learn some-thing new here. And it can give feedback to policy makers, practitioners and re-searchers. The teacher training is to form a big circle of teachers so that they can share their ideas and experiences and to provide course guidance and material for teachers. The organization about CS and industry like Apple, Microsoft usually build a relationship of cooperation. They build platform and provide financial support for the teacher training. In a word, the implementation of perfect education needs efforts from multiple departments.

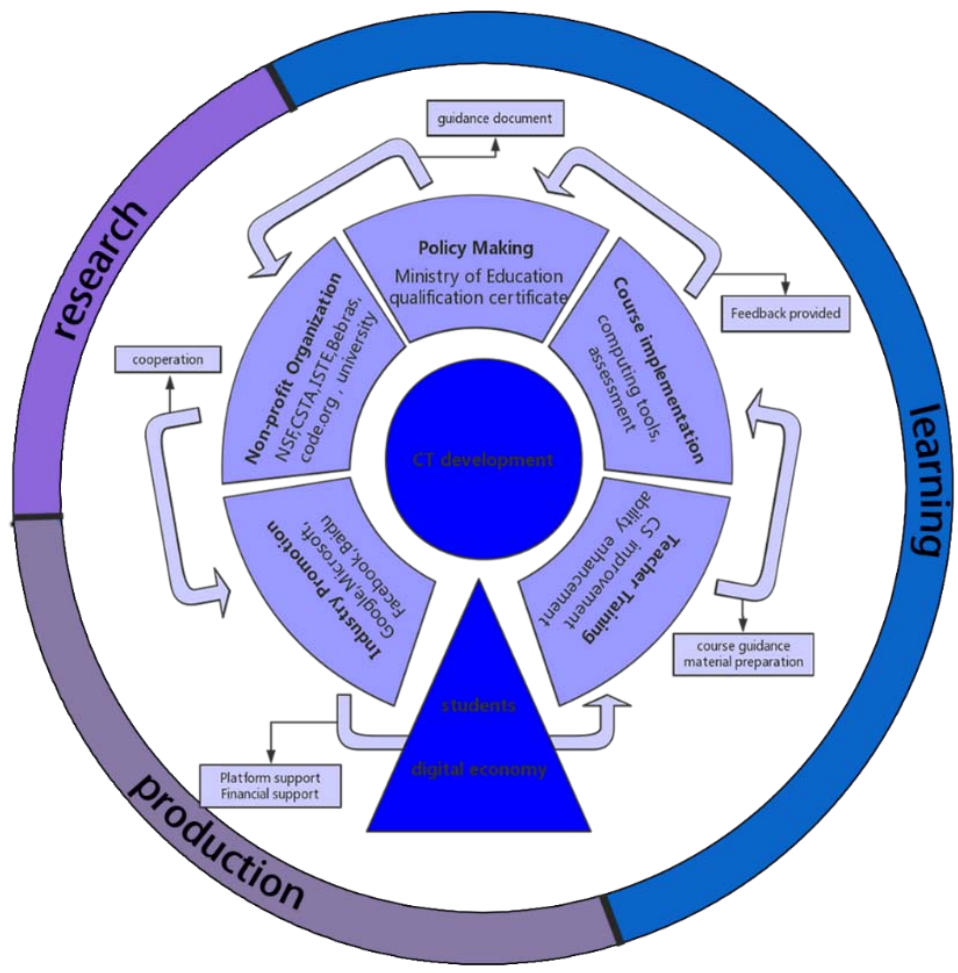

Figure 2. The general development framework. 
Computational thinking is becoming ever increasingly important to our society. However, CT or CS in primary and secondary education has not been well developed. Some measures should be taken to change the current situation. One of the most effective ways is to open up the door of each country so that they can learn from each other. Though every country has different conditions, they can summarize the successful experience and apply it combined with the actual situation. There is also a research comparing and discussing the computational thinking educational policy initiatives emphasizes the trend of collaborative relationships and partnerships that cut across sectors and national boundaries (Hsu, Irie, \& Ching, 2019).

As we all know, cooperation between countries may bring great progress in the economy. It is reasonable to believe that cooperation can also promote the development of education. Here are a few suggestions:

-With the development of transportation, the members of the Ministry of education can visit the CT related course in other countries by themselves. The course implementation can give feedback to the policy making. They can interact with the teachers and students to get first-hand information. As experts of education, their suggestion to the improvement of the course plan is also valuable for the teachers.

-With the developed Internet, the teachers from each country can take part in a public community where they can share the experience of their native curriculum and resolve the questions for each other. Otherwise, it is necessary to build a Competitive relationship. For example, the teachers can make groups of ten formulating a course plan during a semester and comparing the teaching achievement in the end.

- The industry promotion plays a great role in development. The industries like Google may provide financial support or teaching material for the teacher training. They can record the process of the training as videos so that many people can get access to the resource through MOOC. The role of the industries can also be an intermediary to combine the countries together.

\section{References}

Baron, G.-L. (1989). L’informatique, discipline scolaire?: le cas des lycées. PUF, Paris.

Benaya, T., Zur, E., Dagiene, V., Stupuriene, G. (2017). Computer Science High School Curriculum in Israel and Lithuania-Comparison and Teachers’ Views. Baltic Journal of Modern Computing, 5(2), 164-182.

Computer Science to Be Included in the EBacc [DB/OL] (2019). http://www.education.gov.uk/inthenews/inthenews/a00221085/ ebaccompsci. Last accessed 2019/6/26.

Computing in the Core. (2014). http://www.computinginthecore.org/. Last accessed 2019/6/28.

Computing Programs of Study for Key Stages 1-4 [DB/OL](2019). http://computingatschool.org.uk/data/uploads/ computing-04-02-13_001.pdf(2013) Last ac-cessed 2019/6/28.

Conseil Sup’erieur des Programmes. Projet deprogrammes pour les cycles 2, 3, 4. (2015). (French)

CSTA \& ISTE: Operational definition of Computational Thinking in K-12 education. (2009). https://csta.acm.org/Curriculum/sub/ CurrFiles/CompThinkingFlyer.pdf.

CSTA: K-12 Computer Science Standards, Revised 2017. (2017). https://www.doe.k12.de.us/cms/lib/DE01922744/Centricity/ Domain/176/CSTA\%20Computer\%20Science\%20Standards\%20Revised\%202017.pdf.

Dagiene, V. (2006). The Road of Informatics. Vilnius, TEV.

Dagiene, V., Stupuriene, G. (2016). Informatics Concepts and Computational Thinking in K-12 Education: A Lithuanian Perspective. Journal of Information Processing, 24(4), 732-739.

Department for Education: “National curriculum in England (2013): Computing programmes of-study", https://www.gov.uk/government/publications/national-curriculumin-england-computing-programmes-of-study. Last accessed 2019/6/27.

Engelhardt, Katja. (2016). Developing Computational Thinking in Compulsory Education-Implications for policy and practice. JRC104188.

European Schoolnet. (2015). Computing our future:Computer programming and coding Priori-ties,school curricula and initiatives across Europe.

Gal-Ezer, Judith, and Chris Stephenson. (2014). “A Tale of Two Countries: Successes and Challenges in K-12 Computer Science Education in Israel and the United States”. ACM Transactions on Computing Education (TOCE) 14. 2: 1-18.

Grover, S., Pea, R. (2013). Computational Thinking in K-12: A Review of the State of the Field. Educational Researcher, 42(1), 38-43.

Heintz, Fredrik., Mannila, Linda., Färnqvist, Tommy. (2016). A Review of Models for In-troducing Computational Thinking, Com- 
puter Science and Computing in K-12 Education. In: Proceedings Of The 46th Frontiers In Education, pp. 1-9.

Howard, N: EdTech Leaders'Beliefs. (2018). How are K-5 Teachers Supported with the Integra-tion of Computer Science in K-5 Classrooms? Technology, Knowledge and Learning, 24(2), 203-217.

Hsu, Y., Irie, N., Ching, R. (2019). Computational Thinking Educational Policy Initiatives (CTEPI) Across the Globe. TechTrends, 63(3), 260-270. http://www.education.gov.uk/inthenews/inthenews/a00215981/new-industry-backed-plans-to-boost- computer-science-teaching(2013) Last accessed 2019/6/26.

J. M. Wing. (2006). Computational thinking. Communications of the ACM, 49(3), 33-35.

Mannila, Linda., Settle, Amber., Dagiene, Valentina, et al. (2014). Computational Thinking in K-9 Education. ITiCSE-WGR 2014 Working Group Reports of the 2014 Innovation and Technology. In: Computer Science Education Conference.

Ministry of Education of the People's Republic of China. (2018). Information Standards for In-formation Technology in Ordinary High Schools [M]. Beijing: People’s Education Press. (in Chinese)

Ministry of Education of the People’s Republic of China. (2019). Eight provinces released com-prehensive reform plan for college entrance examination, http:/www.moe.gov.cn/jyb_xwfb/gzdt_gzdt/s5987/201904/t20190424_379274.html.(2019). Last accessed 2019/08/27 (in Chinese).

New Industry-Backed Plans to Boost Computer Science Teaching and Help Britain Compete in the World[DB/OL].

Pan, T. -Y. (2017). Reenergizing CS0 in China. In P. J. Rich \& C. B. Hodges (Eds.), Emerging research, practice, and policy on computational thinking. Pp. 351-362. Cham: Switzerland, Springer.

Seymour Paper. (1980). t: Mindstorms: Children, Computers, and Powerful Ideas [M]. New York-Basic Books: 285-286.

Tort, Françoise \& Drot-Delange. (2013). Béatrice. Informatics in the French Secondary Curricu-la: Recent Moves and Perspectives. 7780. 31-42.

Vanea Chiprianov. (2016). Laurent Gallon. Introducing Computational Thinking to K-5 in a French Context. 21st Annual Conference on Innovation and Technology in Computer Sci-ence Education, Jul 2016, Arequipa, Peru.

White House. (2016). “Computer science for all”, https://www.whitehouse.gov/blog/2016/01/30/computer-science-all. Last accessed 2019/6/28. 